\title{
The relationship between financial development and economic growth
}

\author{
Liyang ZHANG \\ School of Economics \\ Renmin University of China \\ Beijing, 100872, China
}

\author{
Yixiao WANG \\ School of Sociology and Population Studies \\ Renmin University of China \\ Beijing, 100872, China
}

\begin{abstract}
Based on the financial development and economic growth in the country panel data analysis, we found: financial development and economic growth in general presents a strong positive correlation because of the different economic base around the large differences among regions. Overall, the eastern region to promote the role of financial development on economic growth is strong, and the central and western regions to promote the role of financial development on economic growth is weak, which can be interpreted as a higher level of financial development is more strong to promote economic growth. Therefore, the government should increase financial support and preferential policies efforts.
\end{abstract}

Keywords- financial development; economic growth; data

\section{INTRODUCTION}

The role of finance in the economy includes: a medium of exchange, mobilizing savings, allocating capital, risk diversification, the supervisory role of corporate governance. In summary, in two aspects: First, provide payment and settlement systems, facilitate trade and economic operation from the blood and pipeline effect; the second is to invest savings and transforming role by mobilizing savings into investment to promote and increase savings configuration and investment efficiency, promote economic growth from the reservoir and engine effects. Modern finance economic growth plays a vital role. Therefore, the study of the relationship between financial development and economic growth has important practical significance. It is relationship between financial development and economic growth. Wellfunctioning banking system through screening to those is most likely to succeed in innovative products and production processes entrepreneur financing and promotion of technological innovation, thus contributing to economic growth. Some classical economists tend to focus on the real economy, but money is a tool to facilitate the transaction, which was "the veil on the real economy." Economic development is to create a demand for financial services, leading to the development of the financial sector and the financial development of economic growth rather than the opposite. But most economists still confirmed that financial development is a necessary condition for economic growth from the perspective of theoretical and empirical research, respectively, from financial intermediaries, financial structure, financial repression and financial liberalization, financial and other factors discussed in the perspective of economic growth effect, they denied the point of view of just a passive reflection of economic growth. In short, the financial development to economic growth has a huge positive effect. On the relationship between financial development and economic growth, economic and financial development in all regions of China is imbalance, financial development and economic growth showed significant regional factor, China as a whole simply reflects the Chinese financial development and economic growth one average, and it did not reveal significant differences between regions.

\section{OVERVIEW OF ECONOMIC GROWTH THEORY}

The economic growth depends on the remaining share of production for the investment, "which distinguishes between productive and unproductive labor categories, and put the division of labor in economic growth.

The proportion of productive labor in the total labor movement, improves labor productivity caused by the division of labor, and it is an important factor in determining the growth of national wealth. In relations division of labor productivity and economic growth of the core issues, the most important theories of economic growth should be based on the evolution of division of labor ", it is a market-based trade that allows a country's economy benefited from the specialized division of labor," the benefits from specialization the size depends on the intricate network of market relations, especially in the domestic and international trade transaction costs which should be very low. The following factors are to achieve rapid growth shortcuts: open international trade, low transportation costs and a wellfunctioning market system. "

Neoclassical growth theory describes a fully competitive economy, which is the growth of output corresponds to the growth of capital and labor inputs, to the formation of the neoclassical growth theory of financial development and the effectiveness of high savings and investment there is a strong positive correlation by transfer surplus funds in different sectors and deficit to promote capital formation and stimulate the development of industry, especially in the financial markets with its special function to gather funds to provide financial support for the successful development of innovative products business, thereby stimulating technological change and stimulating economic growth. Both 
developed and developing countries have the same technology, the developed countries are due to diminishing marginal returns of capital, so developing countries should have faster economic growth than developed countries, per capita income gap between the two should be gradually reduced.

Because neoclassical growth theory can not explain the sustained growth in developed countries and most of the less developed countries have not been able to narrow the development gap, and there is the fact that developed countries will endogenous technological change and other factors that knowledge of human capital in economic growth model is introduced, the elements assume increasing returns the result that the return on capital may change or grow, per capita output can grow indefinitely, and growth in the long term can be individually introduced increasing endogenous technology, which is indicating that technology is no longer exogenous, humans can not control things, but human selfinterest and investment products "new growth theory emphasizes the power to promote long-term economic growth is new business and new products, rather than capital accumulation. Economy human resources (such as scientists and engineers) and specific systems (eg patent law) promote technological innovation, improve living standards", an economy is to take off first before implementing a large number of scientists, and engineers must have" emphasis on investment in knowledge, which can be stable or even increase in the rate of return.

\section{FINANCIAL DEVELOPMENT THEORIES}

System of Finance and Economic Growth in financial development collectively learning theory ", is divided into micro-level and macro levels: micro level focuses on relationship between micro-enterprise performance and the financial system; the macro level focuses on relationship between financial development and economic performance of the country or industry level", which is based on different schools of thought and research perspective, they are divided into: financial structure theory, and the size and structure of the financial difference is the key factor to explain differences in the financial development and economic performance; financial repression theory, the price (interest rate) is variables on the importance of financial development and economic performance of the understanding; functional theory analyzes the financial services and functions "of the financial system for a variety of economic development, the financial the number and size of the structure of financial institutions on a country's financial instruments as well as the structure of the ratio between them, which reflects the level of financial development of the country, and the level of financial development and economic development has close relationship, in economically developed and wealthy country, often the level of its financial development is also high, which includes more number of financial institutions and financial professionals, more and more advanced financial products, large-scale and complex financial assets and other financial markets, " first describe the relationship from the financial and perspectives structure systematic exposition relationship between economic development and growth."
He found that in the period of industrialization in Europe, the bank in the process of capital formation and economic growth is closely related to the role of a country's stage of economic growth", in developed and extreme backward countries, banks in capital formation and economic growth is in a relatively small role, but in relatively backward, the country's economy is rapidly taking off, the bank promotes capital formation and economic growth plays a crucial role" in summary, the financial structure and financial development theory is considered mainly an increase in the number of changes in the financial and banking structures" Their main contribution is: First, to establish a measure of the size and structure of financial indicators for the quantitative analysis laid foundation; the second is initially to reveal a catalytic role of financial development on economic growth, "inadequacies of their research work are mainly in: a little price (interest rate) on the variables of financial development and economic growth," in the long term, the total market automatic clearing can not consider the price tag. "But in reality, the vast majority of countries have carried out more or less interest rate controls, under non-equilibrium conditions in the market, variable interest rates can not be ignored" On the introduction of variable interest rates inhibiting vision research, make up for this shortfall. "Lack research on the financial development and promote economic growth mechanisms (channels)" Further studies on the role of the mechanism leads on financial functions, they are more detailed discussion of the financial development and promote economic growth mechanisms (channels)."

In financial development and economic growth study, foreign scholars have been walking in front, Goldsmith pioneered the empirical research. He uses the value of the GNP financial intermediary assets ratio as a country's financial development indicators, by examining the 35 national data in 103 years $(1860 \sim 1963)$ he found that financial development and economic growth generally occur simultaneously, the economy period of rapid growth is always accompanied by the rapid development of finance. But the downside is that he was not able to specify what is cause and effect.

King and Levine aims at shortcoming of Goldsmith study, sampled 80 countries 30 years of data, the system control the factors that affect growth, which indicates that there is a significant statistical significance of a positive correlation, which has a well-developed financial system, the country with higher economic growth and financial development grows faster, and it is suitable for the opposite situation. Levine's study has led to the search for evidence of financial development which affects economic growth climax.

Levine and Zervos (1996) reflect the stock market through the introduction of a number of development indicators in the regression model, and it extended the analysis of financial intermediaries and Economic Growth. Its findings are banking development, stock market liquidity, they are not only are associated with economic growth in the same period, productivity growth and the rate of capital accumulation has a strong positive correlation between economic growth and productivity growth and it is a good predictor of the rate of economic indictor. 
Research in China started late, and it is relatively low. However, by learning to learn both theoretical researches related to foreign and domestic, scholars have also carried out some qualitative research and quantitative research. These previous studies are mostly based on both theoretical achievements abroad, taking into account the real economic situation, and they use foreign mature empirical analysis, results are in line with China's specific conditions valuable conclusions.

Use econometric model of financial development and economic growth mechanism, use the relevant data in the process of China's economic development, the empirical analysis, we held that technological progress and innovation system is the most critical factor in economic growth, and the role of financial development on economic growth is extremely limited .

Using Granger causality test based on Cobb - Douglas production function measurement under the framework of analysis, we find the relationship between financial development and economic growth between empirical researches. Conclude that economic growth and financial development of two-way causality in the Granger sense, and we come to the specific values of financial development on economic growth in the contribution.

\section{EMPIRICAL ANALYSES OF FINANCIAL DEVELOPMENT AND ECONOMIC GROWTH}

In SC Information rank statistics, the number of SC uses that lags smaller values is more ideal " Meanwhile, according to the characteristics of each variable time series select package intercept and time trend" From the test results, we can see LNGDP, LNF workers R, LNFS and LNFI variable level sequence is not stable, and their first-order differential variable vLNGDP, vLNFIR, vLNFS and vLNF and refuse to contain unit root hypothesis, indicating that their first-order differential time series is stationary, so wee use the typical worker (unit Root Process) time series. "

From Granger causality test theory, there are four possible relations between our country and its economic growth and financial development: first, economic growth has led to financial development, and financial development is demand-driven. "This means that the market continues to expand and products growth must be more effectively spread the risk and better control of transaction costs, and therefore in the process of economic growth and financial development has played a role in promoting better" Second, in the impact of economic growth, financial development, namely the supply of financial development guide type
"Financial resources for the mobilization of those arrested in the traditional sectors, making it possible to transfer to promote economic growth in the modern sector, and to ensure that the investment in the projects of the most dynamic play a fundamental role in" Third, financial development and economic growth has no causal relationship" that the existence of a strong correlation between the two is just a coincidence: economic growth, financial same growth, but they are both by their own logic of development." Fourth, mutual causal relationship between financial development and economic growth is not only financial development but also is the driving force of economic growth, at the same time, economic growth has also brought about the development of financial institutions to promote the financial established markets and deepen financial innovation, thus promoting greater financial development, the interaction between the two doubled promote their development. Here we combine empirical analysis of data.

\section{CONCLUSIONS}

Finance is the core of the national economy; financial development affects economic growth through what channels and mechanisms are an important research topic." On the basis of the existing literature on the theoretical analysis and Chinese-oriented real-world experience, we indepth analyze channels and possible mechanism of the transition and impact of China's financial development and economic growth.

\section{References}

[1] Wu Feng studied. Since the reform and opening Wuxi financial development and economic growth[D]. Jiangnan University, 2008.

[2] Chhen Limin. Relationship between financial development and economic growth in various regions of China[J]. Zhejiang Financial, 2011,08: 31-34.

[3] Guo Lingling. Empirical study of the relationship between financial development and economic growth[D]. Dongbei University of Finance and Economics, 2007.

[4] Wang Yana. China's financial development of regional differences in the relationship between economic growth and research[D]. Jiangsu University, 2007.

[5] Yibireheng. Tibet Autonomous Regional Financial Development and Economic Growth[D] Southwest University of Finance and Economics, 2013.

[6] Li Xin. Research Development and Economic Growth in China's financial [D]. Shandong University,2009.

[7] Zhang Min. Finance and Growth in economic development theory and empirical research [D]. Hunan University,2004. 